\title{
An Unusual Case of Extensive Xanthogranulomatous Orchitis in a Diabetic Patient
}

\author{
Abul Ala Syed Rifat Mannan ${ }^{a}$ Mirza Kahvic $^{a}$ Yahya Abu Sarab \\ Chandramouli Bharatic \\ Departments of a Pathology, ${ }^{\text {b }}$ Urology and ${ }^{\mathrm{C}}$ Radiology, Al Jahra Hospital, Kuwait
}

\section{Key Words}

Diabetes mellitus $\cdot$ Testis $\cdot$ Xanthogranulomatous

inflammation

\begin{abstract}
Objective: We report an unusual case of extensive xanthogranulomatous orchitis (XGO) in association with poorly controlled diabetes mellitus. Clinical Presentation and Intervention: A 65-year-old Kuwaiti man with poorly controlled diabetes mellitus presented with a painful left testicular swelling of 1 year duration. Testicular tumor markers were normal. Scrotal ultrasonography showed a mass lesion of mixed echotexture, which almost replaced the testicular parenchyma. Left-sided orchiectomy was performed with the clinical diagnosis of testicular neoplasia. Subsequent examination revealed the diagnosis of $\mathrm{XGO}$, and the patient is well 2 years after the operation. Conclusion: Extensive tumorous XGO associated with diabetes mellitus has not been previously reported. We offer this case to highlight the implied role of poorly controlled diabetes mellitus in the pathogenesis of XGO.

Copyright $\odot 2009$ S. Karger AG, Basel
\end{abstract}

\section{Introduction}

Xanthogranulomatous inflammation is a rare but distinctive type of chronic inflammation commonly observed in the kidney and characterized by destruction of the affected tissue by a cellular infiltrate of foamy histiocytes with variable admixture of multinucleated giant cells, plasma cells and neutrophils with foci of necrosis. Reported related factors include urinary tract infections, urolithiasis, obstructive uropathy and altered immune responses.

Testicular involvement is a rare event, with 13 cases reported to date [1-7]. We present an unusual case of extensive xanthogranulomatous orchitis (XGO) and discuss the possible role of diabetes mellitus in the pathogenesis of this unusual lesion.

\section{Case Report}

A 65-year-old Kuwaiti with a history of poorly controlled diabetes mellitus presented with 1 year of a painful gradually enlarging left testicular swelling. There was no fever, urinary complaint or history of trauma. Physical examination revealed an enlarged, tender left testicular mass fixed to the scrotal skin. The right scrotal area was normal. Inguinal lymph nodes were not enlarged. Complete blood count and testicular tumor markers were within normal ranges. Ultrasonography of the left testis revealed a circumscribed mass of mixed echotexture, replacing the entire testis

\section{KARGER}

Fax +4161306 1234 E-Mail karger@karger.ch www.karger.com
A.A.S. Rifat Mannan

Department of Pathology, Al-Jahra Hospital

PO Box 62276

Jahra 02153 (Kuwait)

Tel. +9659738 9482, Fax +965 2458 2628, E-Mail mannanrifat@rediffmail.com 


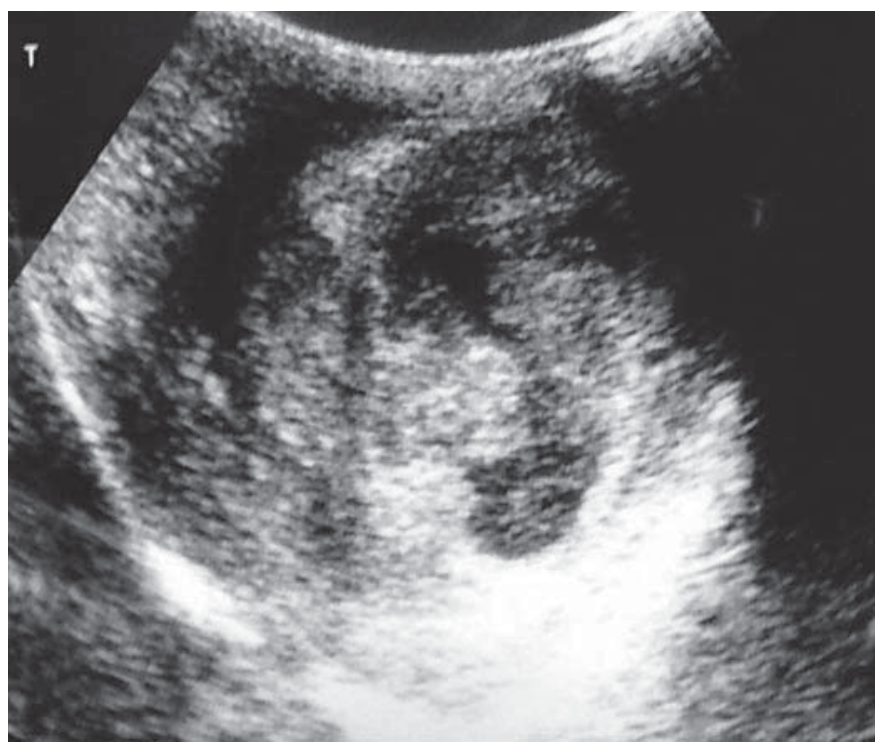

Fig. 1. Ultrasonographic image of the left testis showing a mass lesion of mixed echotexture replacing the testicular parenchyma.

(fig. 1). A thoracic radiogram and an abdominal computed tomography scan did not reveal any abnormality. Left inguinal orchiectomy was performed to exclude malignancy. Microbiology of the mass obtained at surgery showed no significant growth.

Gross examination of the specimen revealed near total replacement of the testicular parenchyma by a $7.5 \times 6 \times 2 \mathrm{~cm}$ illdefined yellow necrotic mass (fig. 2). On microscopy, there was diffuse replacement of seminiferous tubules and interstitium by sheets of foamy histiocytes (fig. 3), intermingled with neutrophils, lymphocytes, aggregates of mature plasma cells and occasional multinucleated giant cells. Inflammation extended to the attached scrotal skin. The epididymis and vas deferens were preserved. Histiocytes showed immunoreactivity for the macrophage marker CD68 and were negative for S-100 protein. Michaelis-Gutmann bodies were absent. Stains for fungi and acid fast bacilli were negative. Given these routine and immunohistochemical microscopic features, a diagnosis of XGO was made.

The postoperative recovery was uneventful, and the patient was well when last seen 2 years after the operation.

\section{Discussion}

Xanthogranulomatous inflammation of the testis is extremely uncommon and, to our knowledge, only 13 cases of XGO/orchiepididymitis have been reported to date [1-7]. All the cases share the characteristic infiltrate of foamy histiocytes, mixed inflammatory cells and occasional multinucleated giant cells, that constitute the histologic hallmarks of the disease.

Xanthogranulomatous Orchitis

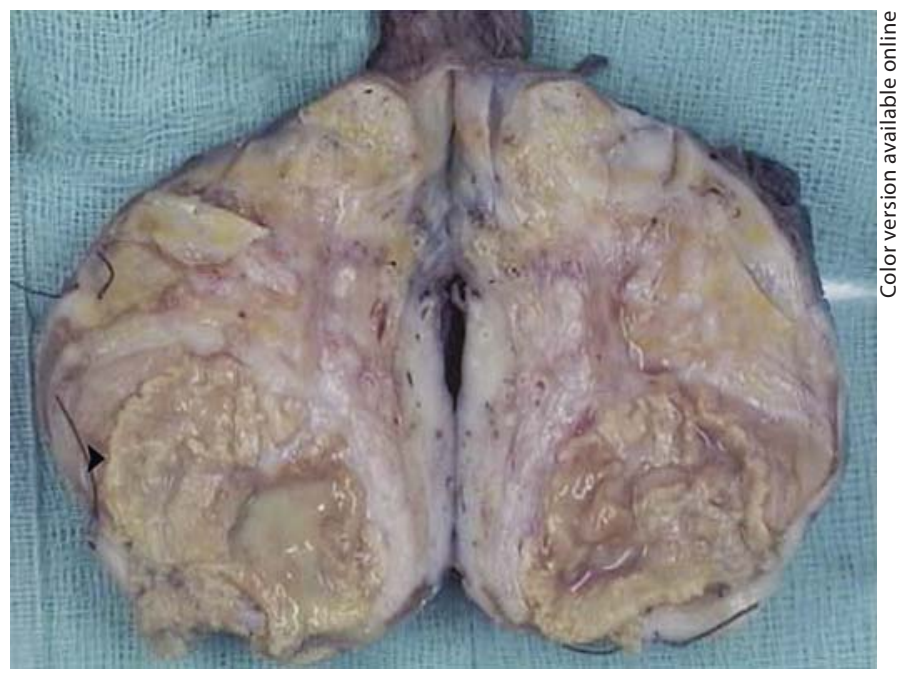

Fig. 2. Gross appearance of the excised testis demonstrating near total replacement of the testicular parenchyma by a yellow mass (arrowhead) with areas of necrosis.

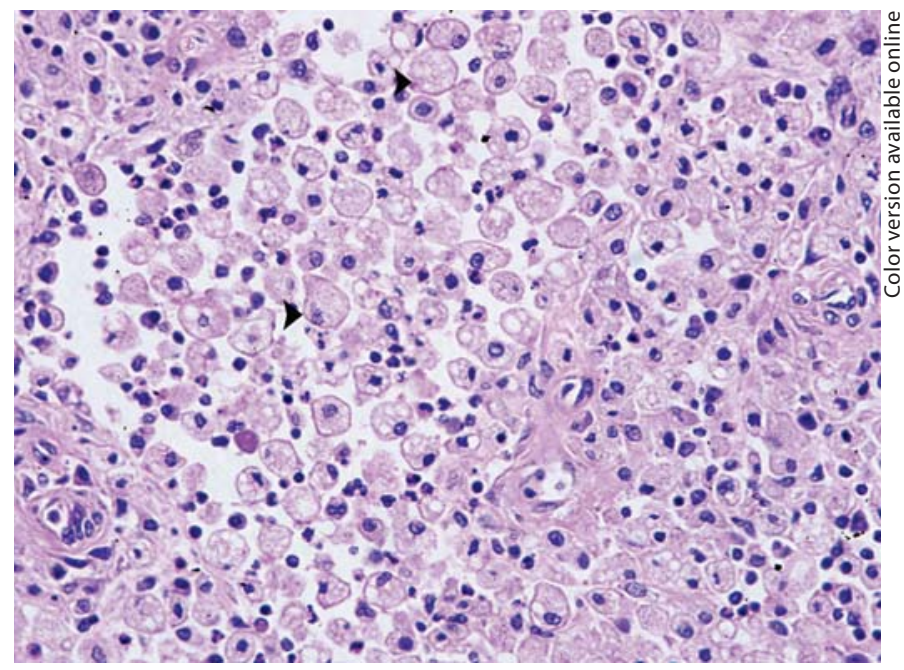

Fig. 3. Photomicrograph showing diffuse infiltration by foamy histiocytes (arrowhead). Hematoxylin-eosin. $\times 400$.

The pathogenesis of xanthogranulomatous inflammation remains largely unknown. Consequently, several possible factors including persistent urinary tract infection, calculous or noncalculous obstruction, abnormal lipid metabolism, altered immunologic response, lymphatic blockage, congenital anomalies and ineffective clearance of bacteria by phagocytes have been suggested

Med Princ Pract 2009;18:418-42 
$[4,5]$. Obstruction of the epididymis or an ischemic process of the testis and genital tract associated with chronic infective inflammation [4], reflux of urine along the ductus deferens [2] and urethral manipulation (surgery/ catheterization) have been considered possible risk factors for the development of XGO. The present case was unrelated to any of these conditions.

Although various infective microorganisms have been implicated in the etiology of xanthogranulomatous inflammation, this remains unproven as microbiological culture often yielded negative results. Escherichia coli has been the most common organism isolated in association with XGO [3, 4]. The failure to identify an infective agent in all the cases may be related to the chronicity of the inflammation and the routine use of prior antibiotic therapy in most cases.

The frequent association of diabetes mellitus with xanthogranulomatous inflammation brings forth a third possible mechanism not previously explored. Diabetes mellitus has been found in as many as 5 of the 14 reported cases of XGO, including the present one $[1,3$, 4]. Diabetic patients are frequently immunocompromised, and all steps of leukocyte activity, including adherence, chemotaxis, phagocytosis and bactericidal activity are impaired [8]. In this context, similarities between xanthogranulomatous inflammation and malacoplakia are worth noting. Malacoplakia is a form of chronic granulomatous inflammation, which commonly affects the urinary tract. Calcified lamellar spherules, called 'Michaelis-Gutmann bodies', set in a background of foamy histiocytes identify this unusual entity. The xanthomatous component is common to both the diseases and, as in XGO, E. coli is the organism most frequently isolated in malacoplakia. The disease is thought to result from the impaired ability of the phagocytes to effectively neutralize microorganisms, possibly due to the diminished release of $\beta$-glucuronidase and low levels of cyclic guanosine monophosphate [9]. In this process, diabetes may induce leukocyte dysfunction [9]. Similar mechanisms may be involved in xanthogranulomatous inflammation. A lysosomal defect of macrophage function has been suggested in xanthogranulomatous pyelonephritis based on ultrastructural demonstration of intracellular bacteria within phagolysosomes [10]. These findings suggest that widespread and atypical site xanthogranulomatous inflammation, as observed in the present case, may result from diminished leukocyte activity under the influence of a systemic illness, i.e. diabetes. Thus, an interaction between bacterial infection, impaired host immune response and di- minished leukocytic function may contribute to xanthogranulomatous inflammation.

Localized xanthogranulomatous inflammation often mimics neoplasia, precluding radiologic diagnosis in most instances. Scrotal ultrasound is helpful in distinguishing scrotal conditions such as torsion, but there are no specific findings that distinguish XGO from testicular malignancy $[4,6]$. Tumor markers are helpful, but some testicular tumors may be negative for serologic markers. Limited use of testicular aspiration biopsy further compounds the problem of obtaining a correct preoperative diagnosis. Hence, the final diagnosis of XGO is often achieved only upon examination of an excised specimen. The differential diagnosis includes malacoplakia and Rosai-Dorfman disease, distinguished by the presence of the characteristic Michaelis-Gutmann bodies in malacoplakia and S-100-positive histiocytes containing phagocytized mononuclear cells (emperipolesis) in Rosai-Dorfman disease. Both were absent in the present case.

Tumorous xanthogranulomatous inflammation is associated with severe tissue destruction, and thus, removal (complete or partial) of the affected organ was the definitive treatment in most reported cases [5-7]. In our patient, considering near total destruction of the testicular parenchyma, orchiectomy was performed with a satisfactory outcome.

\section{Conclusion}

The present case serves as a reminder that XGO is a rare pseudoneoplastic condition and is seldom diagnosed preoperatively as physical and radiologic findings are indistinguishable from those of testicular tumors. It suggests a possible role of poorly controlled diabetes mellitus in the pathogenesis of this unusual inflammatory process.

\section{Acknowledgements}

We are indebted to Professor T.A. Junaid, Chairman, Department of Pathology, Faculty of Medicine, Kuwait University, for the guidance and critical review of the manuscript. 


\section{References}

- Usamentiaga E, Val-Bernal JF, Alonso-Bartolome P, Lopez-Rasines G, del Valle JI, Calabia A: Xanthogranulomatous orchitis. Urology 1998;52:891-892.

2 Vaidyanathan S, Mansour P, Parsons KF, et al: Xanthogranulomatous funiculitis and epididymo-orchitis in a tetraplegic patient. Spinal Cord 2000;38:769-772.

$\checkmark 3$ Hajri M, Amna MB, Derouich A, Ayed M, Zermjani F, Jilani SB: Xanthogranulomatous orchitis. Report of 7 cases. Ann Urol (Paris) 2001;35:237-239.
4 Nistal M, Gonzalez-Peramato P, Serrano A, Regadera J: Xanthogranulomatous funiculitis and orchiepididymitis: report of 2 cases with immunohistochemical study and literature review. Arch Pathol Lab Med 2004 128:911-914.

5 Demirci D, Ekmekcioglu O, Soyuer I, Emirdogan M: Xanthogranulomatous orchitis with scrotal fistulas. Int J Urol 2004;11:686688.

6 Salako AA, Olasode BJ, Eziyi AK, Osasan SA: Xanthogranulomatous orchitis in an adult Nigerian. Int J Urol 2006;13:186-188.

7 Al-Said S, Ali A, Alobaidy AK, Mojeeb E, AlNaimi A, Shokeir AA: Xanthogranulomatous orchitis: review of the published work and report of one case. Int J Urol 2007;14: $452-454$. $\checkmark 8$ Delamaire M, Maugendre D, Moreno M, Le Goff MC, Allanic H, Genetet B: Impaired leukocyte functions in diabetic patients. Diabet Med 1997;14:29-34

9 Chou SC, Wang JS, Tseng HH: Malacoplakia of the ovary, fallopian tube and uterus: a case associated with diabetes mellitus. Pathol Int 2002;52:789-793.

10 Khalyl-Mawad J, Greco MA, Shinella RA: Ultrastructural demonstration of intracellular bacteria in xanthogranulomatous pyelonephritis. Hum Pathol 1982;13:41-43. 